\title{
Avaliação clínica e hematológica em bezerros Nelore infectados experimentalmente com isolados de Babesia bigemina das regiões Sudeste, Nordeste e Norte do Brasil ${ }^{1}$
}

\author{
Carla Lopes de Mendonça2*, Dirson Vieira ${ }^{3}$, Aguemi Kohayagawa4, Maria Aparecida \\ M. Schenk ${ }^{5}$, Cláudio R. Madruga ${ }^{5}$ e josé Augusto B. Afonso ${ }^{2}$
}

\begin{abstract}
Mendonça C.L., Vieira D., Kohayagawa A., Schenk M.A.M., Madruga C.R. \& Afonso J.A.B. 2003. [Clinical and hematological evaluation of Nelore calves experimentally infected with isolates of Babesia bigemina from the Southeastern, Northeastern and Northern regions of Brazil.] Avaliação clínica e hematológica em bezerros Nelore infectados experimentalmente com isolados de Babesia bigemina das regiões Sudeste, Nordeste e Norte do Brasil. Pesquisa Veterinária Brasileira 23(1):00-00. Clínica de Bovinos, Campus Garanhuns, Univ. Fed. Rural de Pernambuco, Cx. Postal 152, Garanhuns, PE 55292-901, Brazil.

A comparative study was made regarding the clinical and hematological alterations caused by isolates of Babesia bigemina from southeastern, northeastern and northern Brazil in experimentally infected Nelore calves. Eighteen calves between 7 and 9 months of age, without antibodies against Babesia sp and raised free from ticks, were used. Three animals were previously inoculated with $2.0 \times 10^{9}$ parasitic erythrocytes $(\mathrm{PE})$ for each stabilate. The other 15 calves were subdivided into three groups, with five animals each, that were subinoculated with $1.0 \times 10^{10} \mathrm{PE}$ of the respective isolates. The clinical and hematological alterations were evaluated by the determination of parasitaemia, haemogram, plasmatic fibrinogen, reticulocyte count, descriptive analysis of the bone marrow and erythrocytic osmotic fragility, for 30 days, totalizing seven moments of observation. The follow-up of the immunological response by the indirect fluorescent antibody test was carried out daily until the $10^{\text {th }}$ day after inoculation (DAl) and after that, on the $15^{\text {th }}, 20^{\text {th }}, 25^{\text {th }}$ and $30^{\text {th }}$ DAl. A mild clinical manifestation of the disease was observed. The laboratory findings revealed low levels of parasitaemia; decrease of the erythrogram values; absence of reticulocytes, initial decrease in the total count of leukocytes, neutrophils and lymphocytes with a posterior elevation of the number of these cells; hypercellularity of the erythrocytic series and decrease of the myeloid: erythroid relation which was more accentuated between the $8^{\text {th }}$ and $12^{\text {th }}$ DAl, and an increase of the erythrocytic osmotic fragility in the groups inoculated with the Southeast and Northeast isolates. None of the three isolates of $B$. bigemina gave rise to the clinical characteristic form of the disease, although they induced an humoral immune response.
\end{abstract}

INDEX TERMS: Experimental infection, Babesia bigemina, calves, brazilian isolates, haemogram, bone marrow, erythrocytic osmotic fragility.

\footnotetext{
${ }^{1}$ Aceito para publicação em 27 de janeiro de 2003.

${ }^{2}$ Clínica de Bovinos, Campus Garanhuns, Universidade Federal Rural de Pernambuco Av. Bom Pastor s/n, Cx. Postal 152, Garanhuns, PE 55290-000. *Autor para correspondência, E-mail: zecarla@ infohouse.com.br

${ }^{3}$ Escola de Veterinária, Universidade Federal de Goiás, Cx. Postal 131, Goiânia, G0 74001-970.

${ }^{4}$ Depto Clínica Veterinária, FMVZ, Unesp-Campus de Botucatu, Cx. Postal 560 , Botucatu, SP 18618-000.

${ }^{5}$ Embrapa Gado de Corte, Rodovia BR 262 Km 4, Cx. Postal 154, Campo Grande, MS 79002-970.
}

RESUMO.- 0 presente trabalho teve por objetivo estudar comparativamente as alterações clínicas e hematológicas desencadeadas por isolados de Babesia bigemina das regiões Sudeste, Nordeste e Norte do Brasil em bezerros Nelore infectados experimentalmente. Foram utilizados 18 bezerros com idade entre sete e nove meses, isentos de anticorpos contra Babesia sp. e criados livres de carrapatos. Três ani-

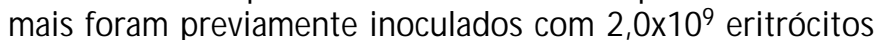
parasitados (EP) para cada isolado. Os outros 15 bezerros foram subdivididos em três grupos de cinco animais, que fo- 
ram subinoculados com $1,0 \times 10^{10}$ EP dos respectivos isolados. Foram avaliadas as alterações clínicas e hematológicas por meio da determinação da parasitemia, do hemograma, do fibrinogênio plasmático, da contagem de reticulócitos, da análise descritiva da medula óssea e da fragilidade osmótica eritrocitária, no decorrer de 30 dias, perfazendo um total de sete momentos de observação. 0 acompanhamento da resposta imunológica pelo teste de imunofluorescência indireta foi realizado diariamente até 010 - dia pós-inoculação (DPI) e posteriormente no $15 \circ, 20 \circ, 25 \circ$ e 30 o DPI. Clinicamente, observou-se uma manifestação muito branda da doença. Os achados laboratoriais revelaram baixos níveis de parasitemia; decréscimo nos valores do eritrograma; ausência de reticulócitos; diminuição inicial na contagem total dos leucócitos, neutrófilos e linfócitos com posterior elevação do número destas células; hipercelularidade da série eritrocítica e decréscimo da relação mielóide:eritróide mais acentuada entre 08 o e 12 o DPI e um aumento da fragilidade osmótica eritrocitária nos grupos inoculados com os isolados sudeste e nordeste. Nenhum dos três isolados de B. bigemina desencadeou a forma clínica característica da enfermidade, apesar de induzirem uma resposta imune humoral.

TERM OS DE INDEXAÇÃO: Infecção experimental, Babesia bigemina, bezerros, isolados, hemograma, medula óssea, fragilidade osmótica eritrocitária.

\section{INTRODUÇÃO}

Algumas enfermidades constituem fatores limitantes ao crescimento da bovinocultura mundial em áreas tropicais e subtropicais, entre as quais se destacam as hemoparasitoses, consideradas como um dos principais entraves à pecuária bovina. Estas doenças limitam o desenvolvimento da indústria e da produção animal (Brown 1997). No Brasil, a babesiose bovina é causada pelos protozoários Babesia bigeminae Babesia bovis, ambos transmitidos pelo carrapato Boophilus microplus (Kessler \& Schenk 1998).

As manifestações clínicas desencadeadas nesta enfermidade são variáveis, podendo-se observar diferentes graus de gravidade, que oscilam em função da virulência e patogenicidade entre as espécies e isolados de Babesia. Quanto à patogenicidade, $B$. bigemina é capaz de desencadear um mecanismo pelo qual acarreta danos celulares e tissulares (Losos 1986).

Diferentes isolados geográficos de organismos do gênero Babesia diferem antigênica e geneticamente (De Vos et al. 1987, Dalrymple 1992), tendo inclusive os isolados de $B$. bigemina utilizados neste trabalho apresentado polimorfismo antigênico (Madruga et al. 1994). Estas variações podem estar relacionadas a maior ou menor grau de virulência, que pode ser observado nos diferentes isolados de B. bigemina. Segundo a literatura, os isolados australianos desta espécie de Babesia não representam um problema sanitário importante, ao contrário dos encontrados na África do Sul, que são altamente virulentos (Purnell 1981, Wright \& Goodger 1988).

Em nosso país são escassos os estudos experimentais enfocando os aspectos clínico-laboratoriais relacionados aos isolados de $B$. bigemina de diferentes regiões fisiográficas, que conforme a literatura, podem apresentar variações na sua virulência. Tendo em vista a importância da babesiose nas regiões tropicais e, pela grande extensão territorial do Brasil, com características ambientais inerentes a cada uma de suas regiões, este trabalho teve por objetivo comparar as alterações clínicas, hematológicas e a resposta imune humoral desencadeadas por isolados de B. bigemina das regiões Sudeste, Nordeste e Norte do Brasil.

\section{MATERIAL E MÉTODOS}

\section{Animais, obtenção dos isolados de Babesia bigemina e inóculo}

Foram utilizados 18 bezerros da raça Nelore (Bos indicus) com idade entre sete e nove meses, criados livres de carrapato e isentos de anticorpos contra Babesia sp. Três desses animais foram esplenectomizados e inoculados por via subcutânea com $2 \times 10^{9}$ eritrócitos parasitados (EP) de isolados de $B$. bigemina provenientes das regiões Sudeste, Nordeste e Norte do Brasil, obtidos segundo metodologia descrita por Kessler et al. (1998) e mantidos criopreservados no Banco de Endo, Ecto e Hemopatógenos da Embrapa Gado de Corte. Estes animais tiveram por finalidade a obtenção de um número uniforme de organismos viáveis para a inoculação e foram denominados de animais doadores. Os outros 15 bezerros foram subdivididos em três grupos de cinco animais, que foram subinoculados, via subcutânea, com $1,0 \times 10^{10} \mathrm{EP}$ dos respectivos isolados de $B$. bigemina.

Todos os animais foram mantidos em área de isolamento em prédio telado, a fim de se evitar a ocorrência de infecções intercorrentes, transmitidas por alguns dos vetores dos hemoparasitos presentes em nosso meio.

\section{Avaliação clínica e parasitológica}

A avaliação clínica foi realizada diariamente no início da manhã, durante 30 dias, efetuando-se a mensuração da temperatura retal, a observação da coloração das mucosas, do comportamento e do apetite dos animais. Paralelamente, confeccionavam-se esfregaços sangüíneos delgados, mediante a punção de capilares da margem da orelha, corados por May-Grünwald Giemsa, a fim de se avaliar a parasitemia (Kessler \& Schenk 1998).

\section{Avaliação hematológica}

A avaliação hematológica foi realizada por meio do hemograma, da contagem de reticulócitos, da determinação do fibrinogênio plasmático, da fragilidade osmótica eritrocitária e da análise descritiva da medula óssea. A colheita das amostras sangüíneas e da medula óssea foram realizadas no 40(momento-M2), 80(momentoM3), 12 (momento-M4), 16 o (momento-M5), $23^{\circ}$ (momento-M6) e 30 (momento -M7) dias pós-inoculação (DPI), sendo o momento controle (momento-M 1) estabelecido antes da inoculação e resultante da média dos valores obtidos de três colheitas realizadas com intervalos de 48 horas.

0 sangue foi colhido mediante punção da veia jugular utilizandose agulhas $25 \times 8$ acopladas a tubos a vácuo, com anticoagulante EDTA a 10\%para realização do hemograma, determinação do fibrinogênio plasmático e contagem de reticulócitos e com heparina sódica (143UI/ $\mathrm{mL}$ ) para determinação da fragilidade osmótica eritrocitária (FOE).

Para a realização do hemograma, da determinação do fibrinogênio plasmático e da contagem de reticulócitos seguiu-se a metodologia descrita por Jain (1986).A colheita da medula óssea foi realizada em seguida à colheita do sangue total, após a contenção dos animais em decúbito lateral e posterior tranqüilização com 0,1 


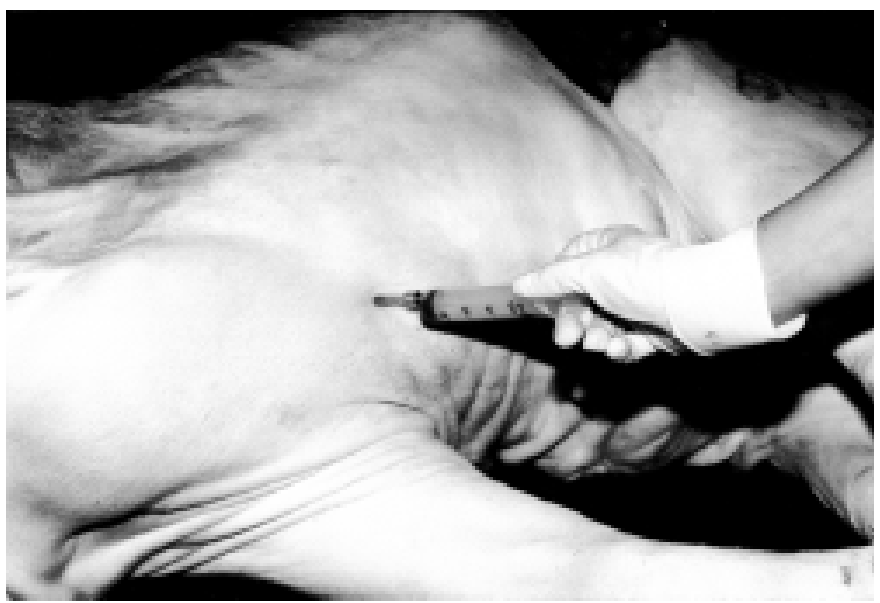

Fig. 1. Colheita da medula óssea no esterno.

$\mathrm{mL}$ de cloridrato de xilazina a $2 \% 100 \mathrm{~kg}$ de peso vivo. Posteriormente à anti-sepsia do local, posicionou-se uma agulha especial (Komiyashiki, Japão) estéril com o mandril sobre o osso esterno e por meio de movimentos rotatórios exerceu-se pressão até que a mesma alcançasse a cavidade medular. Posteriormente, 0 mandril foi removido e conectou-se uma seringa de polietileno de $20 \mathrm{~mL}$, umedecida com anticoagulante EDTA a 3\% diluído em solução fisiológica estéril, a fim de produzir um vácuo para a aspiração do material medular. Aspirou-se o volume máximo de $0,5 \mathrm{~mL}$ de medula por colheita (Fig. 1), sendo logo em seguida realizado os esfregaços do material colhido, que foram corados por May Grünwald-Giemsa. A análise descritiva da medula óssea foi realizada em microscópio óptico com objetivas 10x, 12,5x, 25x, 40x e 100x e ocular 10x, seguindo os critérios descritos por Perkins (1998).

A FOE foi determinada dentro de no máximo uma hora após a colheita, de acordo com a metodologia descrita por Jain (1986). Foram obtidos os valores médios do percentual de hemólise nas diferentes concentrações de $\mathrm{NaCl}$ nos sete momentos analisados. 0 percentual de hemólise contra o percentual da concentração de $\mathrm{NaCl}$, de cada grupo separadamente, em cada um dos momentos, foi plotado em gráfico, obtendo-se uma curva sigmóide. A fragilidade corpuscular média (FCM) foi calculada por meio da análise do probit com o objetivo de expressar a concentração de $\mathrm{NaCl}$, na qual ocorreu 50\%de hemólise (Jain 1986).

\section{Imunofluorescência indireta}

0 sangue para obtenção do soro foi colhido por venopunção em tubos a vácuo siliconizados, diariamente até o 10 이, com a finalidade de detectar a soroconversão e posteriormente no 15 , 20 ㅇ, 25 e e 30 을 para determinar o título de anticorpos. A prova de imunofluorescência indireta (IFI) foi realizada conforme metodologia descrita por Madruga et al. (1986b).

\section{Análise estatística}

Os dados foram analisados, comparando-se as regiões correspondentes aos isolados de $B$. bigemina, e os sete momentos experimentais, utilizando a análise de variância, visando verificar interação entre regiões e momentos; efeito de região e efeito de momento. Foi calculada a estatística $F$ e seu respectivo nível de significância ( $p)$. No caso da estatística resultar significativa $(p<0,05)$, foram efetuados os contrastes entre médias pelo método de Tukey. Para a contagem diferencial dos leucócitos (bastonetes, eosinófilos e basófilos) foi utilizada a prova não paramétrica de Kruskal-Wallis para amostras independentes e a prova não paramétrica de Friedman para amostras dependentes. Para a avaliação da fragilidade osmótica eritrocitária foi realizado o teste " $\mathrm{t}$ " para amostras dependentes a fim de comparar os valores da fragilidade corpuscular média no momento controle com os momentos seguintes à inoculação de cada grupo estudado (Curi 1997).

\section{RESULTADOS E DISCUSSÃO}

\section{Avaliação clínica e parasitemia}

De maneira geral ocorreu uma manifestação branda da enfermidade. Os animais apresentaram apetite, coloração das mucosas e comportamento normais, aliados a uma pequena elevação da temperatura corporal nos primeiros DPI.

Apesar de utilizar bezerros isentos de anticorpos contra Babesia sp., presumivelmente sensíveis ao parasito (Hall et al. 1968); uma quantidade de inóculo superior aos empregados em outros trabalhos (Mangold et al. 1992, Böck et al. 1997) e, a via subcutânea como local de inoculação, os animais, do presente estudo, não manifestaram clinicamente os sintomas característicos de babesiose (Purnell 1981, Radostits et al. 2000).

A susceptibilidade dos animais zebuínos à babesiose tem sido questionada, existindo controvérsia entre autores (Dally \& Hall 1955, Rogers 1971, Rodriguez et al. 1989, Waal 1993, Böck et al. 1997, 1999). Para alguns, a maior resistência à infecção poderia estar relacionada à menor susceptibilidade dos zebuínos ao carrapato vetor (Madruga et al. 1986a, Sartor et al. 1992, Radostits et al. 2000), em virtude da transmissão ineficiente de $B$. bigemina, já que nestes animais a maioria dos carrapatos morre na fase de larva (Gomes et al. 1989), reduzindo a população de ninfas, estágio no qual é transmitido este hemoprotozoário (Friedhoff 1988) ou segundo Aguirre et al. (1990), em decorrência de uma menor taxa de inoculação do agente. Estudos realizados com bovinos da raça Criola (Bos taurus), Hereford (Bos taurus) e Nelore (Bos indicus), demonstraram que $28 \%$ 23\%e 5\%das teleóginas obtidas dessas raças, respectivamente, estavam parasitadas por Babesia sp. (Guglielmone 1992), sendo inclusive citado por alguns autores um maior risco dos animais zebuínos à infecção ao serem introduzidos numa área de estabilidade enzoótica (Aguirre et al. 1990, Nogueira et al. 1991).

Observou-se em todos os grupos elevação da temperatura corpórea no primeiro e segundo DPI, no entanto, o estado febril foi caracterizado apenas em alguns animais dos grupos Sudeste e Nordeste, retornando posteriormente aos valores pré-estabelecidos (Fig. 2). Para Stöber (1993), as temperaturas corporais situadas entre o limite superior ao normal e 40 ㄷ são denominadas de febre branda.

Segundo Mahoney (1977) e Pandey \& Mishra (1977), existe uma correlação positiva entre a elevação da temperatura corpórea e 0 aumento da parasitemia, desta forma 0 aparecimento de febre branda em alguns dos animais estaria relacionada à baixa parasitemia desencadeada pelos isolados de $B$. bigemina. Resultados semelhantes foram relatados por Böck et al. (1997), que encontraram pequena elevação da temperatura corpórea após a inoculação de $B$. bigemina em animais Bosindicus. 


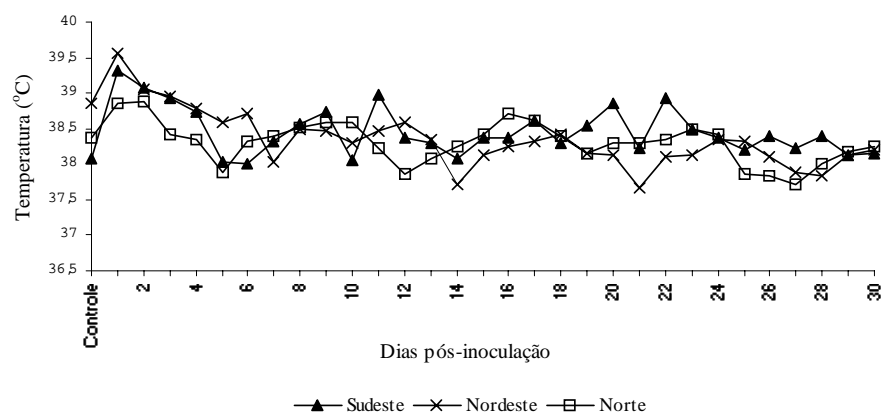

Fig. 2. Valores médios de temperatura retal $(\stackrel{\circ}{ } \mathrm{C})$ de bezerros Nelore inoculados com os isolados Sudeste, Nordeste e Norte de Babesia bigemina.

0 período pré-patente (PPP) foi variável, sendo o parasito observado em alguns animais dos grupos Sudeste e Nordeste a partir do 20 DPI, corroborando os achados de Löhr et al. (1977) e Pandey \& Mishra (1978). Os maiores percentuais de parasitemia 0,05\%(Sudeste) e 0,08\%(Nordeste), foram observados no 4 e e no 7 OODPI. O PPP pode ser reduzido em função da via de inoculação e do número de organismos viáveis inoculados (Mahoney 1977). Em todos os animais verificou-se uma baixa parasitemia, provavelmente relacionada a uma maior resistência dos bezerros nelores ao agente, levando-se em consideração a quantidade de inóculo empregada.

\section{Hemograma}

Não foi verificada diferença estatística significativa $(p>0,05)$ entre os grupos. Após a infecção foi observada diminuição significativa $(p<0,05)$ nos valores médios destas variáveis no 4 o DPI nos animais inoculados com os três isolados de B. bigemina em estudo. Os grupos Sudeste e Nordeste se comportaram de forma mais semelhante no decorrer do experimento, nos quais os valores da contagem de hemácias, volume globular (VG) e hemoglobina se elevaram, sem, entretanto, retornarem aos valores basais pré-estabelecidos (controle). Por outro lado, no grupo inoculado com o isolado Norte, os valores médios destas variáveis alcançaram índices superiores aos outros grupos no $12^{\circ} \mathrm{DPI}$, para então decrescerem e chegarem ao final do experimento, inferiores aos grupos inoculados com os outros isolados e aos valores do momento controle.

Os valores da contagem de hemácias, do VG e da hemoglobina encontrados no momento controle foram semelhantes aos relatados por Ayres (1994) ao estabelecer valores de referência do eritrograma em bovinos da raça Nelore de 6 a 12 meses de idade no Estado de São Paulo. Não ocorreu decréscimo acentuado nos valores da série vermelha, que levassem os animais ao quadro anêmico, no entanto, foi constatada no 4 o DPI uma diminuição significativa $(p<0,05)$ nos valores do VG, na ordem de $22,3 \% 20,7 \%$ e $12,8 \%$ nos grupos Sudeste, Nordeste e Norte, respectivamente (Fig. 3). Estes achados corroboram os encontrados por Löhr et al. (1975), que ao avaliarem a susceptibilidade de animais da raça Boran (Bos indicus) observaram diminuição de $19 \%$ nos valores médios do VG; ao passo que Mangold et al. (1992), observando os achados clínicos de

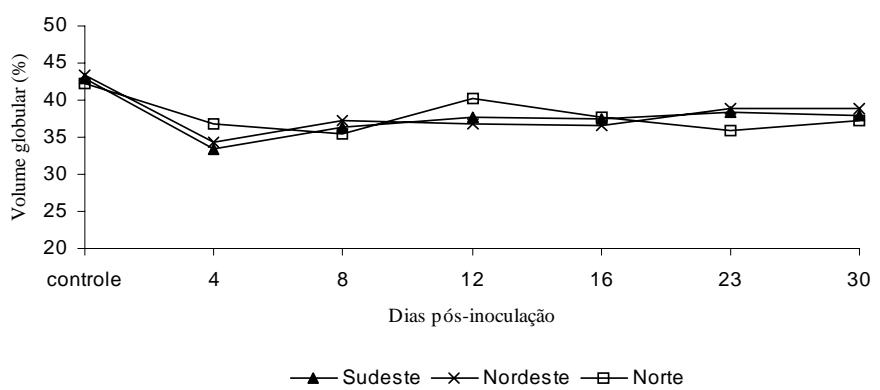

Fig. 3. Valores médios de volume globular (\% de bezerros Nelore inoculados com os isolados Sudeste, Nordeste e Norte de Babesia bigemina.

B. bigemina em bovinos Holando Argentino (Bos taurus) experimentalmente infectados, verificaram um decréscimo de $45 \%$ no VG. Böck et al. (1997), estudando o efeito de B. bigemina sobre animais Bos taurus, Bos indicus e seus cruzamentos, observaram decréscimo nos valores médios do VG que variaram de 22\%a 32\% Os autores atribuiram as leves alterações encontradas ao fato da cepa australiana possuir baixa virulência. Acredita-se que a pequena redução nos valores médios da contagem de hemácias, da hemoglobina e do VG após a infecção, esteja relacionada à baixa parasitemia.

Para Aragon (1976), a anemia ocorre paralelamente ao aumento da parasitemia, em razão de ser resultante da hemólise intravascular, aliada a outros mecanismos como lise e fagocitose de hemácias. Contudo, Murase et al. (1996) relataram que a intensidade da anemia nem sempre é proporcional à parasitemia observada e sugere que os eritrócitos não parasitados possam também ser destruídos por um mecanismo ainda pouco conhecido.

Os valores dos índices hematimétricos não foram similares no decorrer do experimento, havendo interação entre os grupos $(p<0,05)$. No entanto, os valores de VCM e CHCM no decorrer da infecção, foram semelhantes aos encontrados por Ayres (1994) e permaneceram dentro dos valores normais para bovinos da raça Nelore. Na babesiose, a anemia, de maneira geral, é do tipo macrocítica hipocrômica, sendo algumas vezes observada a presença de ponteados basofílicos, o que caracteriza nos ruminantes uma resposta regenerativa da medula óssea (Kohayagawa 1993).

Os reticulócitos não foram evidenciados nos animais inoculados com os diferentes isolados de B. bigemina. Estes achados corroboram as observações de Jain (1986), ao relatar que nos bovinos estas células estão presentes somente após intenso decréscimo do VG. Para Wright (1973), o aumento do VCM e do CHCM coincide com o aparecimento de reticulócitos no sangue periférico de animais infectados experimentalmente por B. bigemina, os quais tiveram diminuição de mais de $50 \%$ nos valores médios do VG. No entanto, Pandey \& Mishra (1977) relataram que os animais acometidos naturalmente por $B$. bigemina apresentaram anemia normocítica normocrômica, não sendo observados reticulócitos no sangue periférico de alguns dos animais acometidos por severa anemia. 


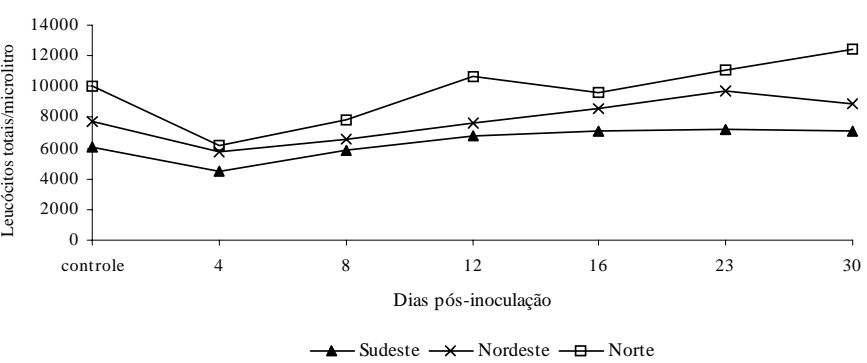

Fig. 4. Valores médios de contagem total de leucócitos (/mL) de bezerros Nelore inoculados com os isolados Sudeste, Nordeste e Norte de Babesia bigemina.

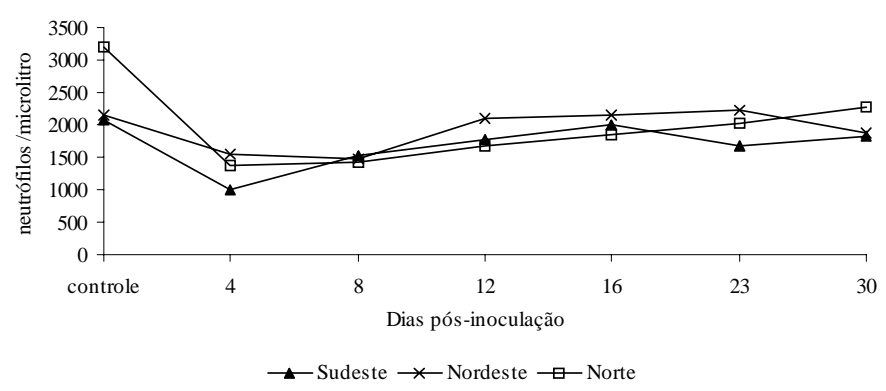

Fig. 5. Valores médios da contagem absoluta de neutrófilos segmentados $(/ \mathrm{mL})$ de bezerros Nelore inoculados com os isolados Sudeste, Nordeste e Norte de Babesia bigemina.

Não foi evidenciada alteração significativa $(p>0,05)$ nos valores das proteínas plasmáticas nos diferentes momentos experimentais. Lozano (1975) relatou a diminuição nos níveis de proteína após a infecção por B. bigemina, que estaria relacionada à diminuição nos valores de albumina, provavelmente associada à uma alteração hepática.

Ao se analisar os resultados do leucograma, verificou-se nos três grupos diminuição significativa $(p<0,05)$ na contagem total de leucócitos no 4 o DPI nos animais inoculados com os isolados Nordeste e Norte. No decorrer do experimento, houve elevação nos valores médios destas células, quando comparadas ao momento controle, que foi significativa nos grupos Nordeste (23익) e Norte (30 DPI). 0 grupo inoculado com 0 isolado Norte apresentou valores superiores $(p<0,05)$ aos demais grupos durante 0 experimento no 12 e 30 DPI (Fig. 4). Os valores absolutos dos neutrófilos segmentados decresceram nos três grupos no 4 o DPI, sendo significativo $(p<0,05)$ nos grupos inoculados com os isolados Sudeste e Norte. Posteriormente verificou-se elevação gradativa e uniforme na contagem destas células nos animais inoculados com o isolado Norte. Não foi observada diferença estatística significativa $(p>0,05)$ entre os grupos em cada um dos momentos avaliados (Fig. 5).

Em todos os grupos verificou-se diminuição nos valores médios dos linfócitos no 4 을, que foi significativa $(p<0,05)$ nos grupos inoculados com os isolados Nordeste e Norte. Em seguida, observou-se aumento gradativo na contagem destas células, alcançando em todos os grupos valores superiores aos do momento controle, que foram significativos

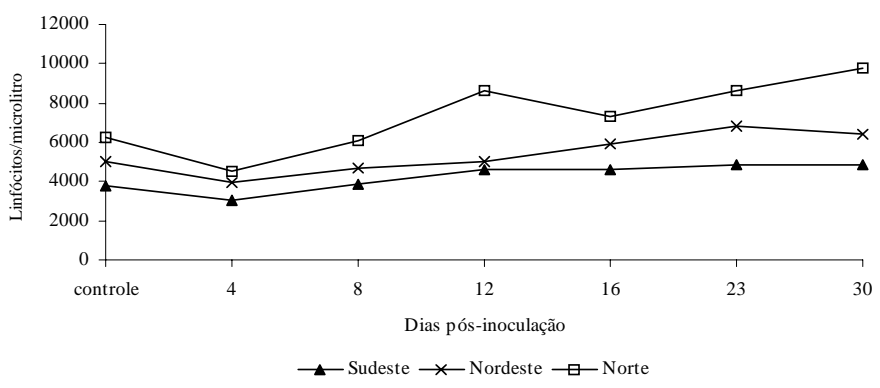

Fig. 6. Valores médios de contagem absoluta de linfócitos $(/ \mathrm{mL})$ de bezerros Nelore inoculados com os isolados Sudeste, Nordeste e Norte de Babesia bigemina.

$(p<0.05)$ nos grupos Nordeste no 23 ㅇ e 30 o DPI e, Norte a partir do 12 - DPI. Ao se comparar os grupos em cada um dos momentos, verificou-se que o grupo inoculado com 0 isolado Norte apresentou valores superiores $(p<0,05)$ ao grupo Sudeste a partir do $8^{\circ}$ DPI e ao grupo Nordeste no $12^{\circ} \mathrm{e}$ $30^{\circ}$ DPI (Fig. 6).

Com relação aos valores absolutos de eosinófilos, foi observado aumento significativo $(p<0,05)$ no decorrer do $23^{\circ} \mathrm{e}$ $30^{\circ}$ DPI nos grupos Sudeste e Nordeste respectivamente, quando comparado ao momento controle. Não foi observada diferença significativa $(p>0,05)$ entre os grupos em cada um dos momentos estudados. Os valores absolutos de bastonetes, monócitos e basófilos não apresentaram alterações significativas $(p>0,05)$ ao longo dos momentos de observação, nem entre os grupos, como também dentro dos grupos inoculados com os diferentes isolados.

Os valores dos leucócitos totais e linfócitos encontrados no momento controle foram inferiores aos relatados por Costa (1994), ao estabelecer valores padrões de referência do leucograma de bovinos da raça Nelore criados no Estado de São Paulo, provavelmente por no presente estudo se estar trabalhando com animais isentos de anticorpos para as principais hemoparasitoses presentes em nosso meio. Para Birgel et al. (1974), nas áreas tropicais e subtropicais os animais estão constantemente expostos às infestações por carrapatos, ocorrendo assim uma premunição contínua nos rebanhos, determinando uma leucocitose por linfocitose nos animais premunidos. De maneira geral, observou-se diminuição nos valores absolutos dos leucócitos totais, linfócitos e neutrófilos quatro dias após a inoculação dos isolados de B. bigemina e elevação das respectivas variáveis nos momentos seguintes, apesar de permanecerem dentro do padrão de normalidade para a espécie bovina (Kramer 2000). Acredita-se que estas alterações não tenham sido mais acentuadas em virtude da baixa parasitemia, não levando ao estabelecimento do quadro clínico da infecção. Kohayagawa et al. (1990) verificaram na fase de parasitemia por Babesiasp, em bovinos premunidos, leucopenia associada à neutropenia, linfopenia e eosinopenia, não detectando alterações significativas dos basófilos e monócitos.

No grupo inoculado com o isolado Norte, verificou-se nos momentos finais uma leve leucocitose em decorrência do 
aumento do número absoluto de linfócitos, quando comparado aos outros grupos, talvez pelo fato de este grupo ter apresentado valores destas variáveis superiores aos demais em todos os momentos do experimento. 0 aumento dos valores absolutos do número de linfócitos nos três grupos em estudo ocorreu provavelmente como conseqüência do estímulo antigênico desencadeado pelos isolados de $B$. bigemina. Resultados semelhantes a estes foram relatados por Wright (1973) e Kamran \& Setty (1995), que observaram nos estágios finais da babesiose uma leucocitose acompanhada de linfocitose. Para Löhr et al. (1977), as respostas leucocitárias na babesiose é dependente da gravidade das infecções. Os valores absolutos de bastonetes, monócitos, eosinófilos e basófilos nos três grupos experimentais permaneceram dentro dos níveis considerados normais para a espécie (Kramer 2000).

\section{Fibrinogênio plasmático}

Após a inoculação, foi observada diminuição significativa $(p<0,05)$ dos valores desta variável nos grupos inoculados com isolados de B. bigemina das regiões Sudeste e Norte, que apresentaram valores mínimos no 8 e e 23 o DPI, respectivamente. No entanto, o grupo inoculado com o isolado Nordeste se comportou de forma uniforme, não sendo constatada diferença significativa $(p>0,05)$. Ao longo dos momentos, não foi verificada diferença significativa $(p>0,05)$ entre os grupos inoculados com os diferentes isolados de B. bigemina (Fig. 7). Apesar de ter ocorrido diminuição nos valores do fibrinogênio, estes permaneceram dentro da normalidade para bovinos (Kramer 2000), descartando a possibilidade de um processo inflamatório ou mesmo de uma alteração hepática. Níveis reduzidos de fibrinogênio foram relatados por Goodger \& Wright (1977) em bezerros infectados por $B$. bigemina em conseqüência de lesão hepática.

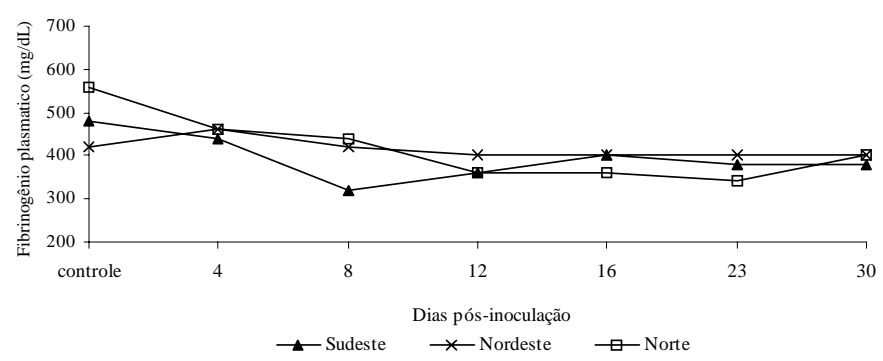

Fig. 7. Valores médios de fibrinogênio plasmático $(\mathrm{mg} / \mathrm{dL})$ de bezerros Nelore inoculados com os isolados Sudeste, Nordeste e Norte de Babesia bigemina.

\section{Medula óssea}

A análise descritiva do aspirado da medula óssea dos grupos em estudo mostrou-se normocelular para a faixa etária dos animais no momento controle, prevalecendo o número de eritroblastos sobre o número de granulócitos, sendo normal a relação mielóide:eritróide para a espécie bovina (Kohayagawa 1993). Ambas as linhagens de células apresen-

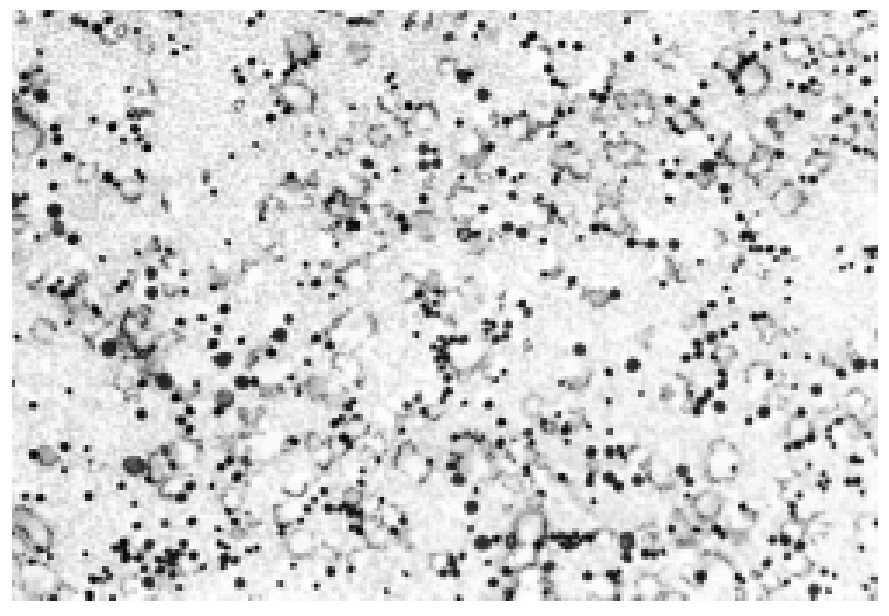

Fig. 8. Esfregaço da medula óssea demonstrando a hipercelularidade da série eritróide.

taram bom número de mitoses e maturação conservada. A série megacariocítica mostrou-se normocelular e com maturação preservada.

Com relação aos linfócitos, foi observada discreta presença destas células no momento que antecedeu a inoculação. Após a inoculação dos isolados de $B$. bigemina nos três grupos em estudo, foi observado no 40 DPI hiperplasia e hipercelularidade absoluta da série eritróide (Fig. 8), tornando-se mais acentuada entre 08 e e 12 ㅇ DPI e discreta no 16 o DPI, para a partir do 230 DPI permanecer normocelular até o final do experimento. Este tipo de resposta evidenciando a proliferação da série eritróide é indicativo de eritropoese eficaz da medula óssea, compensatória para repor as hemácias na circulação sangüínea. Esta hipercelularidade eritróide foi acompanhada do aumento do número de mitoses e policromasia. Cabe ressaltar que nos bovinos, não é comum o aparecimento de reticulócitos no sangue periférico, a não ser em casos severos de anemia (Jain 1986). Entretanto, os resultados demonstraram uma resposta medular como consequência da diminuição do número de hemácias e do VG, acarretando hipóxia e o conseqüente estímulo à eritropoese. Resultados semelhantes foram relatados nos trabal hos de Lozano (1975), após a fase aguda da infecção experimental por B. bigemina, e de Kohayagawa (1993) ao estudar bezerros naturalmente infectados por Babesia sp e Anaplasma marginale.

Foi observada a presença de raras hemácias parasitadas por $B$. bigemina nos esfregaços da medula óssea dos três grupos estudados no 4 o, $8 \div, 12 \circ$ e $16 \circ \mathrm{DPI}$. A série granulocítica apresentou hipocelularidade relativa até o 16 o DPI e se mostrou normocelular a partir do 23 ㅇ DPI com um bom número de mitoses e maturação conservada. Segundo Seybold et al. (1980), esta hipocelularidade não pode ser considerada como uma hipoplasia mielóide, pois ocorreu paralelamente ao decréscimo do VG e da contagem normal do número de leucócitos totais. Observaram-se a partir do 23 o DPI um discreto infiltrado de linfócitos e plasmócitos isolados. Após a inoculação não foram verificadas alterações na série megacariocítica. 


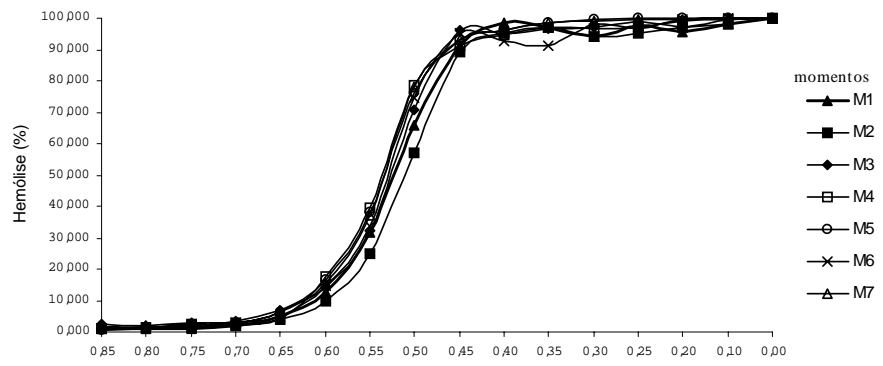

Concentração de $\mathrm{NaCl}(\%)$

Fig. 9. Curva acumulativa da fragilidade osmótica eritrocitária de bezerros Nelore inoculados com o isolado Sudeste de Babesia bigemina em diferentes momentos experimentais.

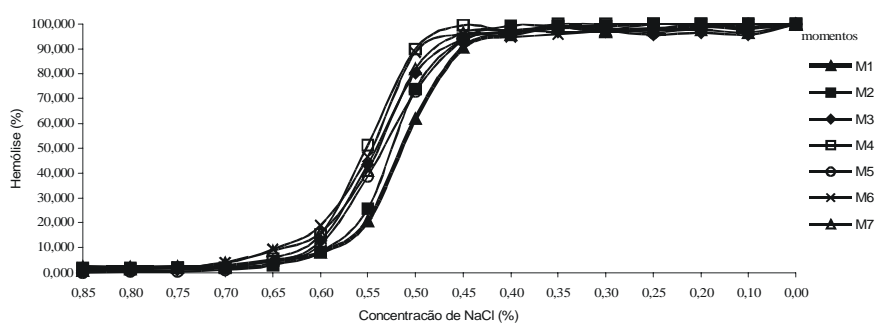

Fig. 10. Curva acumulativa da fragilidade osmótica eritrocitária de bezerros Nelore inoculados com o isolado Nordeste de Babesia bigemina em diferentes momentos experimentais.

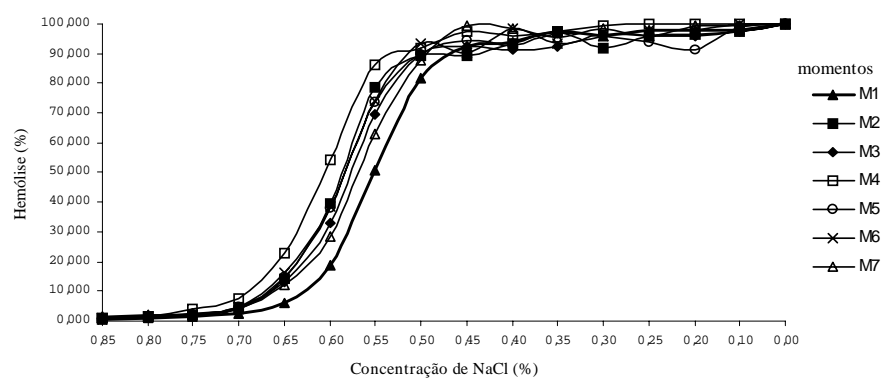

Fig. 11. Curva acumulativa da fragilidade osmótica eritrocitária de bezerros Nelore inoculados com o isolado Norte de Babesia bigemina em diferentes momentos experimentais.

\section{Fragilidade osmótica eritrocitária}

A avaliação da FOE dos três grupos inoculados com os diferentes isolados de $B$. bigemina, possibilitou-nos a análise da curva acumulativa (Fig. 9, 10 e 11). A determinação da FCM permitiu verificar a concentração de $\mathrm{NaCl}$, na qual ocorreram $50 \%$ de hemólise. Observaram-se no momento controle valores médios da concentração de salina de $0,53 \pm 0,04$, $0,51 \pm 0,01$ e $0,55 \pm 0,02$ nos grupos inoculados com os isolados Sudeste, Nordeste e Norte, respectivamente. Os resultados encontrados no momento que antecedeu à inoculação foram um pouco mais elevados que os encontrados por Ayres et al. (1997), ao estudarem a FOE em bovinos da raça Nelore. Provavelmente, estas diferenças estejam relacionadas a determinados fatores extrínsecos, como tempera- tura e pH e intrínsecos, como a faixa etária dos animais estudados (Jain 1986).

Ao analisar os resultados correspondentes à concentração de $\mathrm{NaCl}$ na qual ocorreram $50 \%$ de hemólise, observou-se que nos momentos seguintes à inoculação com o isolado Sudeste, não houve um aumento da FOE (Fig. 10). No entanto, nos grupos Norte e Nordeste, houve aumento da FOE a partir do 4 o e 8 o DPI, respectivamente, que foi mais acentuado no 12 o DPI em ambos os grupos (Fig. 10 e 11). Desta forma, acredita-se que as diferenças destes resultados estejam relacionadas à característica mais hemolítica dos isolados de $B$. bigemina das regiões Norte e Nordeste, apesar de não se ter observado parasitemia mais intensa e nem decréscimo acentuado no eritrograma que evidenciasse anemia nos grupos estudados. Provavelmente, o aumento da FOE possa estar relacionado à liberação de enzimas proteolíticas na circulação sangüínea por esta espécie de Babesia, que segundo Wright \& Goodger (1973), podem contribuir para 0 aumento da fragilidade dos eritrócitos não parasitados.

\section{Imunofluorescência indireta}

Após a inoculação dos bezerros com os diferentes isolados de $B$. bigemina, detectou-se o aparecimento de anticorpos nos grupos Sudeste e Norte no 5o DPI e no grupo Nordeste no 7 o DPI. A partir do 10 o DPI, observou-se um aumento crescente nos títulos de anticorpos contra $B$. bigemina nos três grupos, que, a partir do 20 o dia no grupo norte e 25 o no grupo Sudeste e Nordeste, mantiveram-se estáveis até o final do experimento (Fig.12). Ressalta-se que 0 isolado Nordeste foi o que induziu títulos mais elevados frente ao agente quando comparado aos demais. Resultados semelhantes foram relatados por Dwivedi \& Gautam (1982) que detectaram por IFI anticorpos contra B. bigemina em $74,4 \%$ dos animais no 5 o DPI. Figueroa et al. (1992) e Reddy et al. (1997), utilizando as provas de IFI e imunoadsorção enzimática, respectivamente, detectaram anticorpos contra B. bigemina no 70 dia, que atingiram níveis máximos entre o 21 e e 23으.

De acordo com os relatos de Hildebrandt (1981) e Radostits et al. (2000), os resultados comprovaram que os animais adquiriram a infecção, tornando-se portadores da enfermidade, que foi caracterizada pelo quadro subclínico, mantido

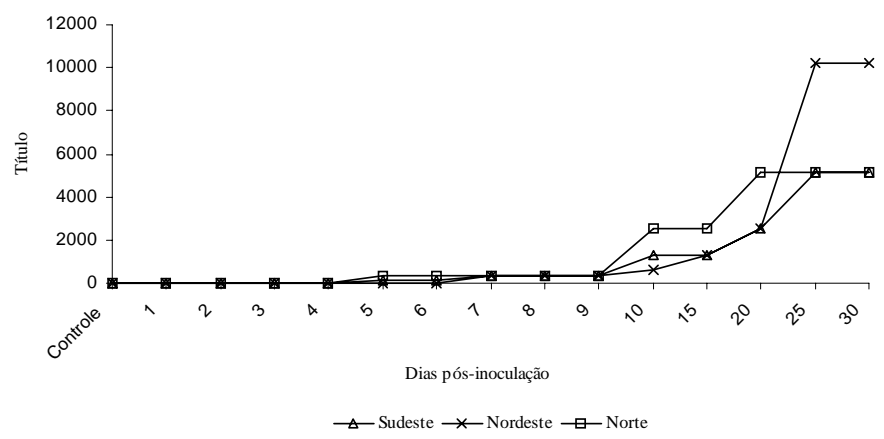

Fig.12. Evolução do título de anticorpos de bezerros Nelore inoculados com os isolados Sudeste, Nordeste e Norte de Babesia bigemina. Detecção por imunofluorescência indireta. 
pelo equilíbrio imunológico entre o hemoparasito e os mecanismos de defesa do hospedeiro. Os isolados de B. bigemina das regiões Sudeste, Nordeste e Norte não desencadearam nos bezerros Nelore as manifestações clínicas e laboratoriais comumente encontradas na babesiose, no entanto, no campo, fatores como condições ambientais adversas e/ou a presença de infecções intercorrentes podem predispor os animais a uma doença clínica grave.

Agradecimentos.- Os autores agradecem à Fundação de Amparo a Pesquisa do Estado de São Paulo (FAPESP) e a Embrapa Gado de Corte (CNPGC), 0 auxílio financeiro e de apoio para a realização deste trabalho. Ao Prof. Dr. Paulo Roberto Curi, FMVZ, Unesp-Botucatu, pelo delineamento estatístico, e ao Dr. Raul H. Kessler, Embrapa Gado de Corte, pela realização das esplenectomias dos animais doadores.

\section{REFERÊNCIAS}

Aguirre D.H., Bermúdez A.C., Mangold A. J. \& Guglielmone A.A. 1990. Infección natural com Babesia bovis y Babesia bigemina en bovinos de raza Hereford, Criolla y Nelore en Tucumán, Argentina. Revta Med. Vet. 71:54-60.

Aragon R.S. 1976. Bovine babesiosis: a review. Vet. Bull. 46: 903-17.

Ayres M.C.C. 1994. Eritrograma de zebuínos (Bos indicus, Linnaeus, 1758) da raça Nelore criados no Estado de São Paulo: influência dos fatores etários e do tipo racial. São Paulo. Dissertação em Clínica Veterinária, FMVZ, USP, São Paulo. 204p.

Ayres M.C.C, Barros Filho I.R., Costa J.N., Mirandola R.M.S. \& Hagiwara M.K. 1997. Determinação da fragilidade osmótica eritrocitária em bovinos da raça Holandesa e zebuínos da raça Nelore. Anais 29 Congr. Bras. Med. Veterinária, Gramado, RS, p. 135. (Resumo)

Birgel E.H., Araújo L.M., Reichman C.E., Araújo W.P., D’Angelino J.L. \& Santos C.O.M. 1974. Influência da premunição no quadro leucocitário de bovinos da raça Holandesa, importados do Canadá. Anais 14을. Bras. Med. Veterinária, São Paulo, p. 161-62.

Brown C.G.D. 1997 Dynamics and impact of tick-borne diseases of cattle. Trop. Anim. Health Prod. 29:15-35.

Böck R.E., Kingston T.G., Standfast N.F. \& Vos A.J. 1999. Effect of cattle breed on innate resistance to inoculations of Babesia bigemina. Aust. Vet. J. 77:465466.

Böck R.E., Vos A J., Kingston T.G. \& Mc Lellan D.J. 1997. Effect of breed of cattle on innate resistance to infection with Babesia bovis, B. bigemina and Anaplasma marginale. Aust. Vet. J. 75:337-40.

Costa J.N. 1994. Leucograma de zebuínos (Bos indicus, Linnaeus, 1758) sadios da raça Nelore criados no Estado de São Paulo: influência dos fatores etários e sexuais. Dissertação em Clínica Veterinária, FMVZ, USP, São Paulo. 124p.

Curi P.R. 1997. Metodologia e Análise da Pesquisa em Ciências Biológicas. Tipomic, Botucatu. 263p.

Dalrymple B.P. 1992. Diversity and selection in Babesia bovis and their impact on vaccine use. Parasitol. Today 8:21-23.

Dally G.D. \& Hall W.T.K. 1955. A note on the susceptibility of British and some zebu-type cattle to tick fever (Babesiosis). Aust. Vet. J. 31:152.

De Vos A.J., Dalgliesh R.J. \& Callow L.L. 1987. Babesia, p. 183-222. In: Soulsby E.J.L. (ed.) Immune Response in Parasitic Infections: Immunology, Immunopathology and Immunoprophylaxis. Vol. 3. CRC Press, Boca Raton, Florida.

Dwivedi S.K. \& Gautam O.P. 1982. A note on comparative efficacy of indirect haemagglutination (IHA), capillary tube agglutination (CA) and indirect fluorescent antibody (IFA) tests in the diagnosis of experimental babesiosis in calves. Indian Vet. J. 59:404-406.

Figueroa J.V., Alvarez J.A., Buening G.M., Canto G.J., Hernandez R., Monroy M., Ramos J.A. \& Veja C.A. 1992. Antibody response to Babesia bigemina infection in calves measured by ELISA and immunoblotting techniques. Revta Latinoam. Microbiol. 34:267-273.
Friedhoff K.T. 1988. Transmission of babesia, p. 23-52. In: Ristic M. (ed.) Babesiosis of Domestic Animals and Man. CRC Press, Boca Raton, Florida.

Gomes A., Honer M.R., Schenk M.A.M. \& Curvo J.B.E. 1989. Populations of the cattle tick (Boophilus microplus) on purebred Nellore, Ibage and Nellore $x$ European crossbreds in the brazilian savanna. Trop. Anim. Health Prod. 21:20-24.

Goodger B.V. \& Wright I.G. 1977. Acute Babesia bigemina infection: changes in fibrinogen catabolism. Z. Parasitenkd. 53: 53-61.

Guglielmone A.A. 1992. Epizootiologia de las enfermedades hemoparasitarias de los vacunos. Revta Cub. Cienc. Vet. 23: 73-108.

Hall W.T.K., Tammemagi L. \& Johnston L.A.Y. 1968. Bovine babesiosis: the immunity of calves to Babesia bigemina infection. Aust. Vet J. 44: 259-264.

Hildebrandt P.K. 1981. The organ and vascular pathology of babesiosis, p.459473. In: Ristic M. \& Kreier J.P. (ed.) Babesiosis. Academic Press, New York.

Jain N.C. 1986. Schalm's Veterinary Hematology. 4th ed., Lea \& Febiger, Philadelphia. 1221p.

Kamran C.A. \& Setty D.R.L. 1995. Changes in leukocyte count in Babesia bigemina infected cattle. Indian Vet. J. 72:1106-1108.

Kessler R.H \& Schenk M.A.M. 1998. Diagnóstico parasitológico da tristeza parasitária bovina, p. 81-90. In: Kessler R.H. \& Schenk M.A.M. (ed.) Carrapato Tristeza Parasitária e Tripanossomose dos Bovinos. Embrapa Gado de Corte, Campo Grande, MS.

Kessler R.H., Schenk M.A.M. \& Madruga C.R. \& Gomes A. 1998. Viability of a method for the isolation of Babesia bovis and Babesia bigemina to create a strain bank from five physiographical regions of Brazil. Revta Bras. Parasitol. Vet. 7:91-94.

Kohayagawa A. 1993. Aspectos laboratoriais e testes de imunofluorescência indireta (IFI) para Babesia bovis, Babesia bigemina e Anaplasma marginale em bezerros da raça Holandesa (Bos taurus) Preta e Branca naturalmente infectados por babesiose e anaplasmose. Tese de Livre Docência, FMVZ, Unesp-Botucatu, SP. 140p

Kohayagawa A., Kuchembuck M.R.G., Papa F.O., Oliveira M.R., Almeida C.T. \& Curi P.R. 1990. Alterações do leucograma de bovinos da raça Fleckvieh (Bos taurus) premunidos contra Babesia spp e Anaplasma spp. Vet. Zootec. 2:47-57.

Kramer J.W. 2000. Normal hematology of cattle, sheep and goats, p. 10751084. In: Feldman B.F., Zinkl J.G. \& Jain N.C. (ed.) Schalm's Veterinary Hematology. 5th ed. Lippincott Williams \& Wilkins, Philadelphia.

Löhr K.F., Otieno P.S. \& Gacanga W. 1975. Susceptibility of Boran cattle to experimental infections with Anaplasma marginale and Babesia bigemina. Zentralbl. Veterinaermed. Reihe B. 22:842-849

Löhr K.F., Otieno P.S., Meyer H., Higgs J. \& Ashford W.A. 1977. Haematological reactions to experimental Babesia bigemina infection in splenectomised and non splenectomised cattle. Zentralbl. Veterinaermed. Reihe B. 24: 508-516.

Losos G.J. 1986. Babesiosis, p. 4-97. In: Losos G.J. (ed.) Infectious Tropical Diseases of Domestic Animals. Bath Press: Avon, Great Britain.

Lozano F.A. 1975. Patogenesis de la babesiosis ocasionada por la Babesia bigemina. Revta Inst. Colomb. Agropec. 10:557-558.

Madruga C.R., Berne M.E.A., Kessler R.H., Gomes R.F.C., Lima J.G. \& Schenk M.A.M. 1986a. Diagnóstico da tristeza parasitária bovina no Estado de Mato Grosso do Sul: Inquérito de opinião. Circ. Téc. 18, Embrapa-CNPGC, Campo Grande, p. 1-40.

Madruga C.R., Kessler R.H., Jesus E.F. \& Sete A.J. 1986b. Imunofluorescência indireta para diagnóstico sorológico de Babesia bigemina e Babesia bovis. Produção de antígenos com cepas isoladas no Estado de Mato Grosso do Sul e avaliação preliminar do teste. Pesquisa em Andamento 32, EmbrapaCNPGC, Campo Grande, p. 1-6.

Madruga C.R., Kessler R.H., Schenk M.A.M., Machado R.Z. \& Vidotto O. 1994. Antigenic characterization of brazilian isolates of Babesia bigemina using monoclonal antibodies. Anais XIV Congresso Panamericano de Ciências Veterinárias, Acapulco, p. 329. 
Mahoney D.F. 1977. Babesia of domestic animals, p.1-52. In: Kreier J.P. (ed.) Parasitic Protozoa. Vol. 4. Academic Press, New York.

Mangold A.J., Bermúdes A C, Anziani, O.S., Abdala A.A. \& Guglielmone A.A. 1992. Efectos clínicos de Babesia bigemina vacunal o patógena en novillos Holando Argentino. Revta Med. Vet. 73:43-45.

Murase T., Ueda T., Yamato O., Tajima M. \& Maede Y. 1996. Oxidative damage and enhanced erythrophagocytosis in canine erythrocytes infected with Babesia gibsoni. J. Vet. Med. Sci. 58: 259-261.

Nogueira F.R.C., Massard C.L. \& Barreira J.D. 1991. Tristeza parasitária bovina. Circular Técnica 12, Pesagro-Rio, 1-13.

Pandey N.N. \& Mishra S.S. 1977. Studies on the haematological changes and blood glucose level in Babesia bigemina infection in indigenous cow calves. Indian. Vet. J. 54:880-883.

Pandey N.N. \& Mishra S.S. 1978. Studies on the clinical symptoms and percentage of parasitaemia in experimental Babesia bigemina infection in cow calves. Indian. Vet. J. 55:139-143.

Perkins S.L. 1998. Examination of the blood and bone marrow, p. 9-35. In: Lee G.R., Foerster J., Lukehs J., Paraskevas F., Greer J.P. \& Rodgers G.M. (ed.) Wintrobe's Clinical Hematology. 10th ed. Williams \& Wilkins, Baltimore.

Purnell R.E. 1981. Babesiosis in various host, p. 25-63. In: Ristic M. \& Kreier J.P. (ed.) Babesiosis. Academic Press, New York.

Radostits O.M., Gay C.C, Blood D.C \& Hinchcliff K.W. 2000. Veterinary Medicine. 9th ed. W.B. Saunders, London. 1877p.

Reddy G.G.D., Mishira A.K., Rao J.R. \& Tewari A.K. 1997. Comparasion of indirect immunofluorescence (IIF) and enzyme-linked immunosorbent assay (ELISA) in detecting Babesia bigemina infection in cattle. Acta Vet. Hung. 45:67-74.
Rogers R.J. 1971. An evaluation of tick fever outbreaks in northern Queensland in recent years. Aust. Vet. 7:405-417.

Rodriguez O.N., Espaine L., Rivas A. \& Rodriguez P. 1989. Epizootiologia de las enfermidades de los bovinos causadas por hemoparásitos en la República de Cuba. Revta Cub. Cienc. Vet. 20:37-56.

Sartor I.F., Faccini J.L.H., Kuchembuck M.R.G. \& Curi P.R. 1992. Estudo comparativo da resistência ao carrapato Boophilus microplus (Canestrini) (Acari) em bovinos das raças Gir, Holandesa e mestiços 1/2 gir-holandês. Vet. Zootec. 4:25-33.

Seybold I.M., Goldston R.T. \& Wilkes R.D. 1980. The clinical pathology laboratory examination of the bone marrow. Vet. Med. Small Anim. Clin. 75:1517-1521.

Stöber M. 1993. Identificação, anamnese, regras básicas da técnica de exame clínico geral, p. 44-80. In: Dirksen G., Gründer H.D. \& Stöber M. (ed.) Rosenberger-Exame Clínico dos Bovinos. $3^{\text {rd }}$ ed. Guanabara Koogan, Rio de Janeiro.

Waal D.T. 1993. Protozoal and rickettsial diseases: babesiosis, p. 584-87. In: Howard J.L. (ed.) Current Veterinary Therapy: Food Animal Practice. 3rd ed. Saunders Company, Philadelphia

Wright I.G. 1973. Observations on the haematology of experimentally induced Babesia argentina and $B$. bigemina infections in splenectomised calves. Res. Vet. Sci. 14:29-34

Wright I.G. \& Goodger B.V. 1973. Proteolytic enzyme activity in the intraerythrocytic parasites Babesia argentina and Babesia bigemina. Z. Parasitenkd. 42:213-20.

Wright I.G. \& Goodger B.V. 1988. Pathogenesis of babesiosis, p. 100-118. In: Ristic M. (ed.) Babesiosis of Domestic Animals and Man. CRC Press, Boca Raton, Florida. 